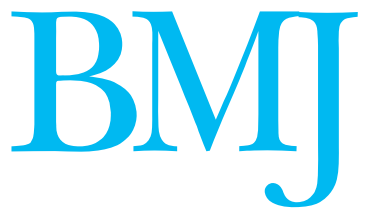

\title{
Tackling health inequalities in the enlarged European Union
}

\author{
Will be essential to making Europe more prosperous and socially just
}

I nequalities in health refer to a broad range of differences in health experience and health status between countries, regions, and social groups. Health inequities are avoidable inequalities that are unfair and unjust. ${ }^{1}$ The UK government has launched a national drive to improve social justice, ${ }^{2}$ and now tackling health inequalities has become a key health theme for the UK presidency of the European Union. To explore the scope for action on social and economic determinants of health the presidency is bringing together European and international experts at the "Tackling Health Inequalities: Governing for Health" summit in London this week.

Earlier this month, the Nobel Assembly at Karolinska Institutet announced its decision to award the Nobel Prize in physiology or medicine for 2005 to Barry J Marshall and J Robin Warren for their discovery of the bacterium Helicobacter pylori, which is associated with chronic disease of the upper gastrointestinal tract. ${ }^{3}$ The prevalence of $H$ pylori differs greatly both between and within countries, with high rates of infection being associated with low socioeconomic status and poor living and housing conditions in childhood. ${ }^{4}$

Most infected people have acquired $H$ pylori infection during childhood, and people with low socioeconomic status who have infected family members are at the highest risk. ${ }^{5}$ In many high income countries, the rate of $H$ pylori infection has fallen markedly over recent decades, and the relatively low rate of infection in young people in developed countries seems to be due largely to improved housing conditions during this century. ${ }^{6}$

Despite the recent decline in prevalence of infection in the new EU member states, ${ }^{7}$ the infection is still considerably more common among the populations of central and eastern European countries than in western Europe. ${ }^{8}$ How to reduce this difference and its accompanying morbidity and mortality is known, and this difference should concern European policy makers as much as those in national governments.

Overall, the citizens of the central and eastern European countries tend to have poorer health and shorter life expectancy than those in western Europe. Compared to the body of evidence on health inequalities within western European countries, however, the social determinants of health in the transition countries of central and eastern Europe have been researched less. The available data provide persuasive ties in several of these countries, for instance in Estonia during the transition period after 1991.

The difference in life expectancy at birth between Estonian and Russian men resident in Estonia increased from 0.4 to 6.1 years between 1989 and 2000 , mainly owing to increasing differences in alcohol related adult mortality. Between 1989 and 2000, differences in total mortality related to educational level among adults increased for all age groups in Estonia: life expectancy at age 25 increased in university educated men and women but declined by more than two years in those educated only to lower secondary school level or below. ${ }^{10}$ There is some good news. For example, the recent achievements in reducing neonatal and infant mortality in Estonia to levels comparable with many European countries are quite remarkable. But the accompanying increase in health inequality due to disproportionately greater improvements among more advantaged social groups in mean birth weight and reduction in rates of preterm births remains a cause of concern. ${ }^{11}$

Successful collaborative projects on health inequality across Europe have tended to focus on documenting and monitoring socioeconomic gradients in ill health and mortality. Despite the methodological difficulties in making valid comparisons of inequalities in health between socioeconomic groups defined in various ways, this research has yielded valuable information on the dynamics of health inequalities over time and across countries, showing - to varying degrees in all societies-that health inequalities are not immune to policy intervention.

Now other dimensions of social position such as ethnicity, gender, age, religion, and place of residence are attracting increasing interest, and underlying social and biological mechanisms that are clearly relevant to inequality in specific health outcomes are being uncovered. Evidence on long term effects of early life environment, intergenerational mechanisms in transfer of health and social disadvantage, and the availability of "life course" methodological approaches ${ }^{12}$ open yet further possibilities for better understanding the aetiology of health inequalities between and within countries.

Health inequalities across Europe as a whole are large, with some regions of Europe increasingly lagging behind. This concerns many citizens in Europe and ought to be tackled by European institutions. Current attempts to promote European links and stimulate 
concerted action to reduce health inequalities are timely. These efforts should not remain restricted to policies implemented within member states of the European Union and should also stimulate and contribute to tackling health inequality across countries and beyond the union's borders.

Ilona Koupil professor of health equity studies

Centre for Health Equity Studies (CHESS), Stockholm

University/Karolinska Institutet, 10691 Stockholm, Sweden

(ilona.koupil@chess.su.se)

I thank Denny Vågerö and Olle Lundberg for helpful discussions and comments.

Competing interests: None declared.

1 Leon DA, Walt G, Gilson L. International perspectives on health inequalities and policy. BMJ 2001;322:591-4.

2 Department of Health. Tackling health inequalities: a programme for action. 2003. www.dh.gov.uk/assetRoot/04/01/93/62/04019362.pdf (accessed 10 Oct 2005)

3 Nobelprize.Org. Press release: the 2005 Nobel Prize in physiology or medicine http://nobelprize.org/medicine/laureates/2005/press.htm (accessed 8 Oct 2005)
4 Mitchell H, Mégraud F. Epidemiology and diagnosis of Helicobacter pylori infection. Helicobacter 2002;7(Suppl 1):8-16

5 Czinn SJ.Helicobacter pylori infection: detection, investigation, and management. J Pediatr 2005;146:S21-6.

6 Fall CHD, Goggin PM, Hawtin P, Fine D, Duggleby S. Growth in infancy, infant feeding, childhood living conditions, and Helicobacter pylori infection at age 70. Arch Dis Child 1997;77:310-4.

7 Oona M, Utt M, Nilsson I, Uibo O, Vorobjoba T, Maaroos HI. Helicobacter pylori infection in children in Estonia: decreasing seroprevalence during the 11-year period of profound socioeconomic changes. Helicobacter 2004;9:233-41.

8 Vyse AJ, Gay NJ, Hesketh LM, Andrews NJ, Marshall B, Thomas HI, et al. The burden of Helicobacter pylori infection in England and Wales. Epidemiol Infect 2002;128:411-7.

9 Leinsalu $\mathrm{M}$, Vågerö $\mathrm{D}$, Kunst AE. Increasing ethnic differences in mortality in Estonia after the collapse of the Soviet Union.J Epidemiol Community Health 2004;58:583-9.

10 Leinsalu M, Vågerö D, Kunst AE. Estonia 1989-2000: enormous increase in mortality differences by education. Int J Epidemiol 2003;32:1081-7.

11 Koupilova I, Rahu K, Rahu M, Karro H, Leon DA. Social determinants of birthweight and length of gestation in Estonia during the transition to democracy. Int J Epidemiol 2000;29:118-24.

12 Kuh D, Power C, Blane D, Bartley M. Socioeconomic pathways between childhood and adult health. In: Kuh D, Ben-Shlomo Y, eds. A life course approach to chronic disease epidemiology. 2nd ed. New York: Oxford University Press, 2004: 371-95.

\section{Complementary therapies and the NHS}

\section{Uncertain evidence of cost effectiveness should not exclude complementary medicine from reviews and guidelines}

$\mathrm{I}$ $\mathrm{n}$ the early 20th century, scientific medicine emerged as the dominant model for health care in the West. Yet, despite the successes of scientific medicine, people have continued to seek treatments outside mainstream services. ${ }^{1}$ In the United Kingdom about one in 10 of the adult population consults a CAM (complementary and alternative medicine) practitioner every year, and $90 \%$ of this contact happens outside the NHS. ${ }^{2}$

Why do people turn to these therapies? Persistent symptoms and the real or perceived adverse effects of conventional treatments are the main reasons. ${ }^{\mathrm{wl}}$ Patients value complementary practitioners viewing their predicament "as a whole" and not through the fragmenting lens of clinical specialisation or within the time pressured environment of primary care. ${ }^{\mathrm{w} 2}$

The popularity of a clinical method should not, however, be confused with its value. The popularity of CAM may simply reflect the limitations of conventional treatments. In the past 20 years there has been substantial research on its effectiveness. By March 2004 the Cochrane Collaboration had 145 completed reviews of randomised controlled trials of complementary and alternative therapies: a third showed a positive or possibly positive effect, although over half found insufficient evidence to make such judgments. ${ }^{3}$

This work has met with resistance from CAM practitioners. ${ }^{\mathrm{w} 3}$ Many of the methodological objections they raise (the individualising of treatments, the integrity of the practitioner-patient relationships, the subtle and long term outcomes expected) are shared by complex interventions for chronic conditions within mainstream health care. ${ }^{4}$ Methodological responses have included pragmatic trial designs, nested qualitative studies, and the use of real world observational data to create an "evidence house."
With finite resources, the case for CAM in the NHS will be judged on economic grounds. But the growth in evidence on clinical effectiveness for some complementary and alternative treatments is not matched by evidence of cost effectiveness. This is the main conclusion one can draw from Canter and colleagues' short report in this issue (p 880). ${ }^{6}$ Looking for randomised studies of complementary or alternative therapies done in the United Kingdom, the authors could locate only five papers for review, four of which reported trials of spinal manipulation. Though the review does not formally assess study quality, it reports that manipulation may be cost effective. In its narrow focus, however, the report fails to address the complexities of cost effectiveness studies in complementary and alternative medicine.

By contrast, the multi-method inquiry by Smallwood published last week spawned a broad, if not sprawling report. ${ }^{8}$ Smallwood was commissioned by the Prince of Wales to investigate whether CAM could save the NHS money in the treatment of chronic conditions. His findings are based on a literature review of studies from the United Kingdom of the big five CAM traditions (acupuncture, homoeopathy, chiropractic, osteopathy, and herbal medicine), ${ }^{9}$ costed case studies of the provision of CAM in primary care, and interviews with favourably disposed stakeholders.

The report is not clear about the method of the unsystematic literature review and contains no explicit appraisal of study quality nor synthesis of data on cost. Owing to a paucity of data, Smallwood does not reach any definitive conclusions about the cost effectiveness of CAM but does identify potential savings. For example, a week's supply of St John's wort, with effectiveness

Additional references w1-w3 are on bmi.com

Papers p 880 